\title{
REQUIREMENTS FOR PARTICIPATIVE MANAGEMENT AS A SOURCE OF SUSTAINABLE COMPETITIVE ADVANTAGE AND TIPICAL MANAGEMENT METHOD
}

\author{
Emanoil MUSCALU* \\ emanoil.muscalu@yahoo.com
}

Alexandru RIZESCU**

rizescu_alexandru@yahoo.com

Alexandru Marius RIZESCU**

mariusrizescu@yahoo.com

\author{
*"LUCIAN BLAGA" UNIVERSITY OF SIBIU, SIBIU, ROMANIA \\ **"NICOLAE BĂLCESCU" LAND FORCES ACADEMY, SIBIU, ROMANIA
}

\section{ABSTRACT}

The economic context in the recent years has undergone major changes in modern methods and techniques used in management. The current competitive environment is characterized by permanent turbulences influencing firstly the managerial act itself. Out of the many methods and techniques applied so far, some turn out to be less adaptable to the current economic and social context.

In the same train of ideas, the organizations always looking for sources of competitive advantage have the tendency of applying innovation and the new in the field. Another trend noted in the current management is that of going towards using operational management methods that enable the replacement of the current descriptive empirical management with certain regulatory and scientific methods.

From this point of view the study aims to highlight the competitive advantage generated by applying the participative management as a management method used within the organizations in order to obtain a better efficiency of the economic activities.

\section{Keywords}

Competitive advantage, management methods, participative management, organizational culture, managerial culture, efficiency, effectiveness

The managerial and the organizational theories largely started with the acknowledgement of the importance of the employees and of the organizational climate for the effective and efficient functioning of an organization. Differentiated research and analyses have covered this issue, gradually shaping the dynamics of the organizational development according to the employees' evolution. 


\section{Introduction}

The economic situation in recent years has undergone radical changes in terms of the specific management methods, systems and techniques. It affected the balance of the energy, capital, raw materials and labor resource markets. The main factors which caused these unbalances were: inflation, financial crisis, housing crisis, the crisis in the food sector, the natural gas and oil price fluctuations. These imbalances had the effect of reducing foreign capital which led to a decrease in the pace of economic development [1].

The industry has also been globally affected, industries such as steel, energy, transport and telecommunications. This has been possible because the focus was laid on the quantity of the production and not on the basic concepts such as quality and market price and thus the concept of strategic vision for managing the organizations has been abandoned.

The success of the management of an organization is closely linked to the strategy adopted for managing that specific organization and applying the strategic management to achieve the mission and the objectives of the organization. Over time it has been determined that, regardless of the type or size of the organization, the degree of competitiveness of the organization in the challenging environment in which it operates, is directly proportional to the quality, objectivity and clarity of the strategies that the certain organization adopts and uses. By its nature, an organization requires an economic activity conducted over a specific period of time, with some goals, more or less consciously undertaken by the initiator of that particular activity.

Post-modern society is influenced by major changes that require new approaches in the organizations' dealing with the environment and implicitly with management thinking and practice. Change imposes on the organizational management a different rhythm, new rules and requirements, causing its regenerative, discovery, imaginary, innovation and learning capacity. In the organization of the beginning of the third millennium - the critical resources are related to the intellectual capital, the skills, the intangible assets, tacit or explicit knowledge, organizational processes and practices. As a result, the methods and the skills needed for the administration of larger or smaller organizations will be totally different from those used in the past for increasing performance and acquiring success. The efficient managers of knowledge-based organizations will have the responsibility to create those organizational and managerial cultures where the promotion and the implementation of the avant-garde models or ideas is an opportunity available only to those considered venturous or creative.

The current competitive environment is characterized by permanent turbulences influencing mainly the act of leading itself. These turbulences are caused by the decrease of the demand, by the poor quality of products, by the intense growth of the price of assets, especially of the real estate ones, and by the competition's emergence with something better to outperform. The current economic environment is also defined by a slower pace of economic development compared to the previous years as a consequence of the decline in labor productivity, the depreciation of currencies and the increase of interest rates and unemployment. The competitive advantage depends on the managerial skill, the brand image, the marketing skills, the product distinction, on fructifying the scale economies, on knowledge about the market requirements, on the possibility of using the capital resources and on controlling transport and distribution.

The organizational, sociological, psychological and managerial theories mostly started with the discovery of the importance of the people and of the socialhuman climate for the efficient functioning of an organization. Multiple analyses and research have been devoted to this issue, gradually configuring the dynamics of the 
human factor of the organization and the management.

There is a strong tendency in using certain operational modes that allow the replacement of the descriptive - empirical management with certain regulatory and scientific means. The management and the current and future trends of the business environment in Romania, of all economic agents, have a very strong contextual determination superior to the situation in other countries, due to the transition to a new economic, political and social system. Consequently, pointing out, even briefly, some of the main processes governing the market economy in Romania, is a prerequisite of analyzing the management models applied to the current economic environment, of shaping the structure and the functionality of the organizations, of understanding and improving their management in general.

First, as pointed put by the majority of economic thinking trends, the market economy is an economic system characterized by the fact that the objective pursued by the economic agents is to maximize profit, the management and the operation of the organizations being achieved by the predominant use of the economic leverages.

The emergence in theory and in practice of a wide array of management methods is explained by the increase of the managerial efficiency applying one management method or another, compared to the companies where the management does not apply a coherent leading method.

Mihaela Vlasceanu emphasizes that ,the success of the $21^{\text {st }}$ century organizations will mostly depend on searching, discovering and efficiently using skilled managers or those imaginative hard working multiqualified persons, full of curiosity, perseverance, focused on ideas, able to encourage diversity, paying attention to the challenges of the environment, with continuous availability of turning vision into reality" [2].

\section{Methods and Techniques of Management}

The approximately 100 currently known management methods and techniques undergo a continuous improvement process in order to respond to the technological evolution and to the increasing demands of the beneficiaries of the activity conducted by the organization.

The methods are generally classified according to several criteria: the intended use, the pursued objective, its nature, the management functions in whose exercise are mostly used, the management subsystems in which they are used. We must make the distinction from the early beginning between the management methods and the methods used in management. The latter are methods economic, technical, sociological, etc. in nature whose use does not affect directly the content and the form of manifestation of the managerial relations and processes. Typically, they belong to the organizational management because of their effectiveness. For example: the matrix of discoveries, the brainstorming, the value analysis, the Monte Carlo method, etc.

The management method or technique is a primary unit, which cannot be deconstructed without abolishing it or changing its structure and purpose. The management techniques are usually intended for achieving the managerial duties assigned to one or more managers. Instead, the managerial systems are broader than the management methods or techniques, and usually contain them in some form or another.

A method that meets the requirements and is often used is the leading method. It refers to the way in which the manager uses the available tools and exercises his authority over the elements at his disposal to use them wisely and effectively and to achieve his goals. Another method used is that of the management whose stages and elements are precisely drawn and strictly organized in a functional complex that facilitates the exercise of elements of the managerial process, with consequences on the activity and the work efficiency of one or more managers. 
The leading methods are effective ways to fructify social work, to direct the endeavors towards meeting the set goals. In the economy what matters is the style the manager adopts for managing an enterprise. Among the most important leadership styles we might mention the following: the autocratic style, the persuasive style, the consultative style, the democratic style.

The autocratic style implies the means in which the decision-maker makes decisions without consulting his associates and subordinates and without taking into accounts their views and proposals. Continuing the enumeration, the persuasive style is how the manager makes decisions without asking the opinion of his collaborators and staff, but he does his best to implement their decisions and to obtain their consent. In the same vein, the consultative style refers to the situation when the manager consults his staff and subordinates in decision making. The democratic style is applied when the manager adopts the decision made following the approval of his fellow workers and subordinates.

From the multitude of methods, techniques and procedures used at the moment, some turn out to be less adaptable to the current economic and social context. Among these methods, techniques and procedures currently used are: the CSROEPM synthesis, the psycho-sociologic and motivational leadership, the Harzburg synthesis, the leadership through communication etc.

The CSROEPM synthesis was developed by H.W. Bayliss and involves synthesizing the leadership methods most commonly used in the current management without bringing innovative elements. The name of the method is an acronym of the most important issues in the proposed system: Communication, Systems, Results, Objectives, Exceptions, Participation, Motivation. This method consists of determining what is inherent and elementary in each of the available means and then gathering these issues in a clear and harmonized whole. It always starts with communication because it influences and generates the communicative attitude which aims to create a participative attitude and to actually involve the fellow workers in the company's problems. However, the CSROEPM synthesis has two drawbacks: it does not clearly envisage budget management and equally the result is directly proportional to the achieved performance.

The Harzburg synthesis abbreviated $\mathrm{SH}$ is also known as the "collegial leadership" or "the Harzburg model". It was theorized by the Management Academy in Harzburg. This method involves combining the methods of leading through objectives, exceptions and results in a system that seeks the cooperative relations, to shape and define the function of a co-worker and to confine the function of leader, to train the personnel in a new conviction, to delegate the decisionmaking capacity etc. One of the suggestions of the Harzbug synthesis is to use more the delegation of power which shall be communicated to the stage where the decision can be made most knowledgeably, this does not definitely mean by the most appropriate, but by the best informed.

The psychosocial and motivational leadership method aims at the dynamism of the group and its motivation. This method consists of encouraging the personnel not to stop only at performing their job requirements but to use their skills to reach their potential in order to solve the various problems that arise in the organization. Among the less new but very often used in practice leadership methods, we must mention: the methods of assessment (SWOT analysis, etc.), the meeting (information, decision, harmonization, exploitation, the heterogeneous meetings), the delegation, the dashboard, the business plan, brainstorming, the Synectics method, the Delbecq method, the Delphi method, etc.

\section{Means of Directing the Participation}

Currently, the participative management is an efficient, effective and modern management system. It can be practiced with great results only if there is a trend, a tendency toward the same goal by all 
employees of an organization, regardless of their hierarchical positions within the organization. In this situation are created those fundamentals needed to consensually establish the objectives and the medium and long-term program, to fundament the decisions and to put them into practice.

Because of the accelerated changes of the nature of the goods and services, it is required that the organization focus its attention on the market segment, and not on the product. "A business is not defined by the name of the company, by its charter or by its articles, but it is defined by the need a customer meets when buying a product or a service provided by the company. The question: "What is our business?" can be answered only by addressing a perspective which allows to look at this business from the outside, i.e. from the point of view of the consumer or of the market segment" [3].

In terms of management, the participation is the activity by which the employees of an organization take part in the management process, getting involved both in setting goals and in implementing them effectively and efficiently in practice. The participation involves bringing together two specific actions: the involvement and the integration.

Nowadays managers must be able to cope with the complex and numerous changes occurring in the economy such as social bonds, demographic changes, and activities aimed at encouraging internal development and acquisitions. The strategic planning gives managers the opportunity to know the future challenges and the opportunities that arise. Due to the amplified close ties of dependency in the external environment of the organizations, the current management can no longer make decisions based only on domestic considerations, as it should incessantly consider the laws, the public opinion, the wishes of the shareholders, the work ties and other external parties. Otherwise, the needs or the requirements of the customers must be the top priority in establishing the organization's mission because ,an organization is distinguished by the quality of the goods that satisfy customer requirements" [4].

The Swedish School of Management, represented by Jonas Ridderstrale and Kjell Nordstrom, promotes specifically the identification of "the niche opportunities" [5] as a source for obtaining the competitive advantage. In their attempt to differentiate themselves from their competitors, the organizations seek the niche, seek to speculate continuously and mostly justified their skills and innovation in the field. The participative management encourages the development of creativity and innovation so that the members of the organization would see it as a challenge to achieve the best results. At the same time, the participative management aims at motivating the staff to provide quality services through appreciating the merits they had after some interesting ideas and proposals and to boost them towards advanced knowledge through self-improvement and training. It is mainly envisaged to reward and encourage the members' contribution to the improvement of the organizational performance which is contained in the organization's strategic objectives. Objectives such as increasing the company's profitability, the competitive advantage held by the company, and the market share are just some of the aspects of the competitive advantage.

In terms of the organization, it contributes to the economic efficiency with leverages such as: involving the company's staff in the decision making processes, creating favorable conditions for the employees which aim at facilitating the participation in making important decisions related to the prosperity of the enterprise, the design and the preservation of the strategic advantage through team spirit, a factor which is valued through the competitive skills of the personnel. In order to achieve superior performance, there must be common objectives, constructive criticism to encourage the development of individual skills and also there must be a higher hierarchical superior which should be an example for the 
company's personnel and should motivate them to obtain an optimal degree in order to reach the maximum performance.

"The participative management system has the main objective of building the management skills, adapting the future leaders with the problems that may arise, stimulating the capability to solve them through creative methods" [6]. Insecure leaders are not successful in supporting the participative management of two reasons: they either aspire to have assumed control over all things, or are afraid to be replaced by someone more competent. In both cases "such leaders will fail to achieve a participative management because they underestimate their own potential and destroy the best efforts of the people they work with" [7].

Only the strong leaders can instill courage and confidence in others by assigning them with responsibilities and creating competent teams that bring the success and the prestige of the organization. Besides "we must not use only the brains we have, but all the brains we can borrow" [8], because it is the only way to ensure the efficiency of the economic activity. There are advantages of implementing the participative management such as increasing the quality of the decisions due to the use of knowledge and managerial skills of the members of the company, enhancing the participation of the stakeholders in setting and achieving the company's goals and also increasing the awareness of the organization's members. Searching for the competitive advantage in itself does not necessarily lead to success in the competition. The explanation is the lack of a stimulating domestic environment for the companies. "They can conduct a good activity depending on how they appear, organize, and are managed, and on the intensity of the market rivalry. Their own management methods and their interfering with those of other companies create a competitive environment specific to an economy, which will bring some advantages and disadvantages to the organization" [9].
Using a participative management leads to the formation of skills within the organization that will facilitate the introduction of transformation, change, permanent innovative practices and increased organizational performance. In the organizations where the organizational culture and the work climate are strong, the employees work together efficiently, share the vision and the mission of the organization and make joint efforts to create appropriate work conditions for each employee.

\section{Conclusions}

The participative management aims at the organization achieving superior performance at all levels: economic, organizational, technical, psychological, commercial etc.

Leadership, participation and culture are so intertwined that they are incomprehensible one without the other. The leadership and the organization generate a certain culture, and the latter shapes the former in such a way so that no leap over time is possible. We cannot escape the dominant culture of the day, just as we cannot transplant the managerial or organizational models developed elsewhere. Each individual person has his place in the culture of the organization he belongs to, just as the latter provides the framework and even the measure of the individual achievement.

We believe that the participative management aims at the collectivism because there are several alternative ideas due to the contribution of the members of the company and there is also a lesser chance of making the wrong decisions. Within this type of management the focus falls on exploiting ideas generated by employees and co-workers in order to make a decision to entail the best results and the efficiency of the organization. From this point of view our research highlighted the competitive advantage generated by applying the participative management to the organizations in order to achieve the efficiency of the economic activities. 
We also consider that the participative management is characterized by the dynamism and the complexity of the economic activities, the technical and scientific development, the need to establish and use of the material and moral incentives so that to ensure the full agreement of the interests of all involved parties.
In conclusion, the participative management can become the true source of a sustainable competitive advantage for the organization. In the present situation of the technological evolution, the organizations must be open to trying to find new development opportunities and must not wish a withdrawing attitude compared to the economic competitors.

\section{References}

1. Lupu A.-G, Lupu F.A., Microeconomie aplicată, (Ploieşti: Karta Graphik Publishing House, 2012), 54.

2. Vlasceanu, Mihaela, Organizaţii şi comportament organizaţional, (Iaşi: Polirom Publishing House, 2003), 283.

3. Drucker, P.F., Realităţile lumii de mâine, (Bucharest: Teora Publishing House, 1999), 86.

4. Drucker, P.F., Inovaţia şi sistemul antreprenorial, (Bucharest: Enciclopedic Publishing House, 1993), 129.

5. Ridderstrale J., Nordstrom H., Funky Business, (Bucharest: Publica Publishing House, 2007), 87.

6. http://www.libruniv.usb.md/bibliouniv_rev/articole/2012 - 1/harconita management part. pdf.

7. Maxwell, John C., Cele 17 legi ale muncii în echipă, (Bucharest: Amaltea Publishing House, 2005), 45.

8. Willson W., Notele stenografiate ale lui Woodrow Wilson, www.bookcity.ro/librariata.

9. Porter M., Competitive Advantage of Nations, (New York: Free Press, 1985), 67. 